\title{
Esthetics in Orthodontics: Interest points, reference points and discrepancy points
}

\author{
Carlos Alexandre Câmara'
}

\begin{abstract}
It is fundamental for orthodontists and all professionals related with facial, oral and dental esthetics to know how the individuals observe dentofacial structures. Thus, it will be the purpose of this Orthodontic Insight to present and describe the Interest, Reference and Discrepancy. Points With the knowledge and perception of these points it will be easier for orthodontists to create a convergent canal of communication with their patients.
\end{abstract}

Keywords: Esthetics. Beauty. Orthodontics.

É fundamental para os ortodontistas e todos os profissionais que estão envolvidos com a estética facial, bucal e dentária conhecer a forma como os indivíduos observam as estruturas dentofaciais. Sendo assim, será o objetivo desse artigo apresentar e descrever os pontos de Interesse, de Referência e de Discrepância. Com o conhecimento e percepção desses pontos, será mais fácil para os ortodontistas criar canais convergentes de comunicação com os seu pacientes.

Palavras-chave: Estética. Beleza. Ortodontia.

Esthetics is the rational study of beauty, from the possibility of its definition,to the diversity of emotions and feelings that it raises in man. ${ }^{1}$

This definition, apparently simple, of the meaning of the word Esthetics, which can be found in several dictionaries, ${ }^{1}$ hides an extremely broad sense. The study and search of its real meaning in the Western world goes back to the greek philosophers such as Plato, Aristotle and Plotinus. The complexity of the term Esthetics is the result of several philosophical theories that sought a consistent explanation for its meaning. The word Esthetic came to designate the general field of Esthetics, which included all categories for which the artists and thinkers had shown

${ }^{1}$ Specialist in Orthodontics (UERJ).

» The author reports no commercial, proprietary or financial interest in the products or companies described in this article. interest, such as Tragic, Sublime, Gracious, Laughable, Humorous etc.; saving the word Beauty for that special type, characterized by harmony, by the sense of measure, by the calm and serene fruition. ${ }^{2}$ Esthetic is, then, this kind of reformulation of the entire Philosophy in relation to Beauty. And, considering the complexity of the esthetic field comes the dilemma created by the irrational temptation: Beauty is in the eyes of the beholder or it is intrinsic to the object? Although this question cannot be solved in an easy way, for it is about a philosophical approach that each individual interprets in their own manner, it can and must be assisted on its conception, especially for orthodontists that work with dentofacial esthetics.

How to cite this article: Câmara CA. Esthetics in Orthodontics: Interest points, reference points and discrepancy points. Dental Press J Orthod. 2012 Sept-Oct;17(5):4-7.

Submitted: June 22, 2011 - Revised and accepted: August 10, 2012

Contact address: Carlos Alexandre Leopoldo Peersen da Câmara

E-mail: cac.ortodontia@digi.com.br 
Thus it is important that every professional that deals with orthodontic treatments with esthetical purpose is aware and alert to the parameters that affect the perception of Beauty, the type of beauty that really matters in an orthodontic treatment. Among these parameters there are concepts of esthetic evaluation that are very important for its perception. From these concepts the Interest Points, Reference Points and Discrepancy Points will be presented in this insight. Although the examples presented in this insight are in the sagittal view, the Interest Points, reference and discrepancy are presented in all plans of observation.

\section{INTEREST POINTS}

It is fundamental for orthodontists and all professionals that are involved with facial, buccal and dental esthetics to know how people observe a face. By tradition the clinician uses his own experience and empathy to predict what the observer can or must extract from a facial analysis, but he does not

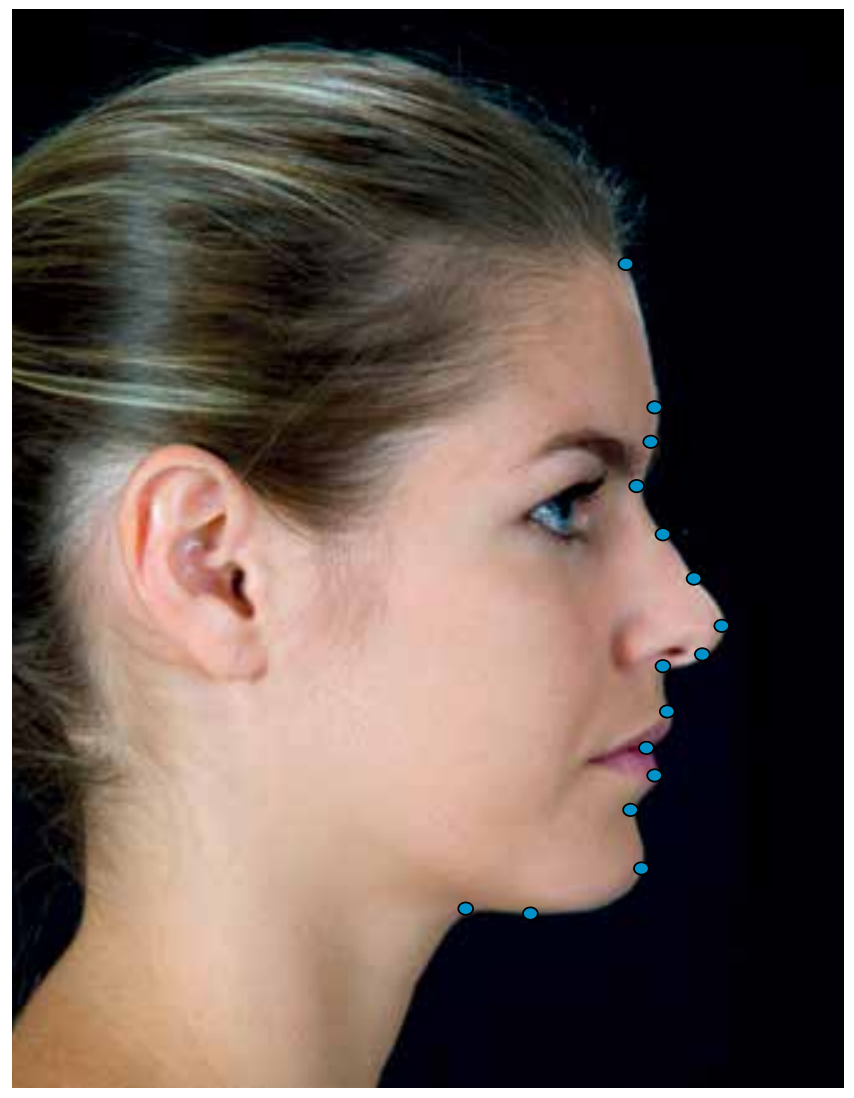

Figure 1 - Sagittal view with Interest Points (in blue) located in the facial profile line. The Interest Points includes the following characteristics: angles, maximum curvatures (concave and convex) and unpredictable contours. always obtain the correct result. The eye-tracking technique provides an experimental proof about how people observe a scene or an image. In the pioneer study performed by Yarbus, ${ }^{3}$ in 1967, the author observed that the eye scans the image in quick jumps, moving from a focus of interest to another. These eye movements he denominated saccades and each point where the eye stops and observes "Interest Points". The explanation for this phenomenon is due to the fact that the central part of the retina, the fovea, has high resolution; and the succession of saccades allows the brain to build a total view on the short term memory. It is possible to follow the saccadic eye movements and register the course of the look. However, this process is so quick (the saccades last between 20 to 200 millisecond) that most people do not notice their observation pattern. In approximately one second it is possible to focus in two or three Interest Points, also called points of fixation. The steady look pattern is affected by factors as news, complexity and incongruity. The moments of eye fixation, that occur during the observation of simple pictures, indicate that the Interest Points correspond to the angles of the picture. Other points that also call attention are the point of maximum curvature, unusual details and unpredictable contours. ${ }^{3}$

This acquaintance of the Interest Points created by the visualization of objects leads to the necessity to comprehend which are the Interest Points in a dentofacial esthetical analysis. As said before, the studies that sought an understanding of the main Interest Points show that the eye searches for spots and lines that are within three main characteristics: angles, maximum curvature (concave and convex) and unpredictable contours. The acquaintance of this information allows a facial analysis much more objective and effective. Recognizing the observed areas it is possible to evaluate more accurately the facial regions and characteristics that directly interfere on the dentofacial analysis, assisting and facilitating the comprehension of factors that affect positively and/or negatively for the creation of Beauty. From the Interest Points it can be derived another two concepts that assist and explain better its perception. They are: Reference Points and Discrepancy Points. 

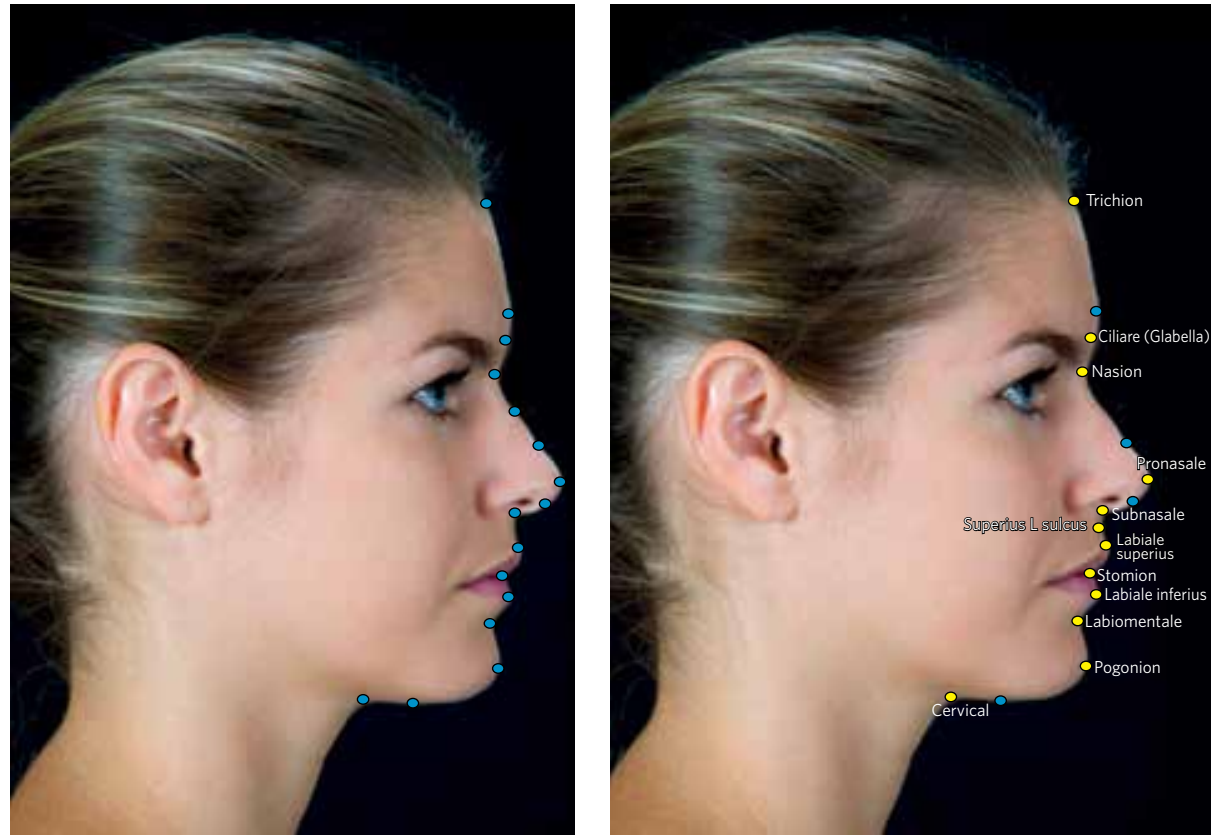

Figure 2 - Sagittal view with Interest Points (in blue) and points of anthropometric references (in yellow) located in the facial profile line. Notice that the Interest Points include all Reference Points and some other points (in blue) that call attention from the observer.

\section{REFERENCE POINTS}

Reference Points are to locate, guide and limit structures of study units. They allow to see in a different way the studied structures.

When we observe an object we have the tendency to stick to the whole image. That is natural, for an unpretentious look search the information in a global way. However, for those who seek to interpret rigorously, the attention to details is fundamental for a correct evaluation. In these cases the recognition of Reference Points is necessary for the structure to be analyzed accurately and deeply. In an esthetical analysis the determination of Reference Points is the initial step for a correct interpretation of the structure. To determine these points must be the first accomplishment of the analysis. With the Reference Points identified, the study of the object becomes simpler. It is possible to delimit the structure, as well as to perceive its proportions. Reference Points give conditions to observe the limits of the analyzed structures facilitating the study of the object, because with the delimitation of what is been observed it is much easier and objective to analyze its components. Worth remembering that Reference Points used in facial analysis are from craniofacial anthropometry and to facilitate the orientation and assure uniformity on the anthropometric terminology the points are named in Greek or Latin. ${ }^{4}$

\section{DISCREPANCY POINTS}

The human cerebral observation and interpretation is capable of evaluating both what pleases us and what displeases us. However, we frequently find difficulty to identify and measure the details that makes an object beautiful or ugly. In another words, although the general perception of beautiful and ugly is easy and inherent to all individuals, the capacity to identify the specific location of the error is not always easy. Therefore, the Discrepancy Points are derivative from Interest Points and facilitate the visualization of flaws. These points are seen every time that a solution of continuity occurs in lines that design and delimit specific structures. While the Reference Points indicate the location of the points that delimit the structures, the Discrepancy Points show the flaws. That is, every time that an unexpected or unwanted interruption occurs on the tracing of a line that represents the picture of 

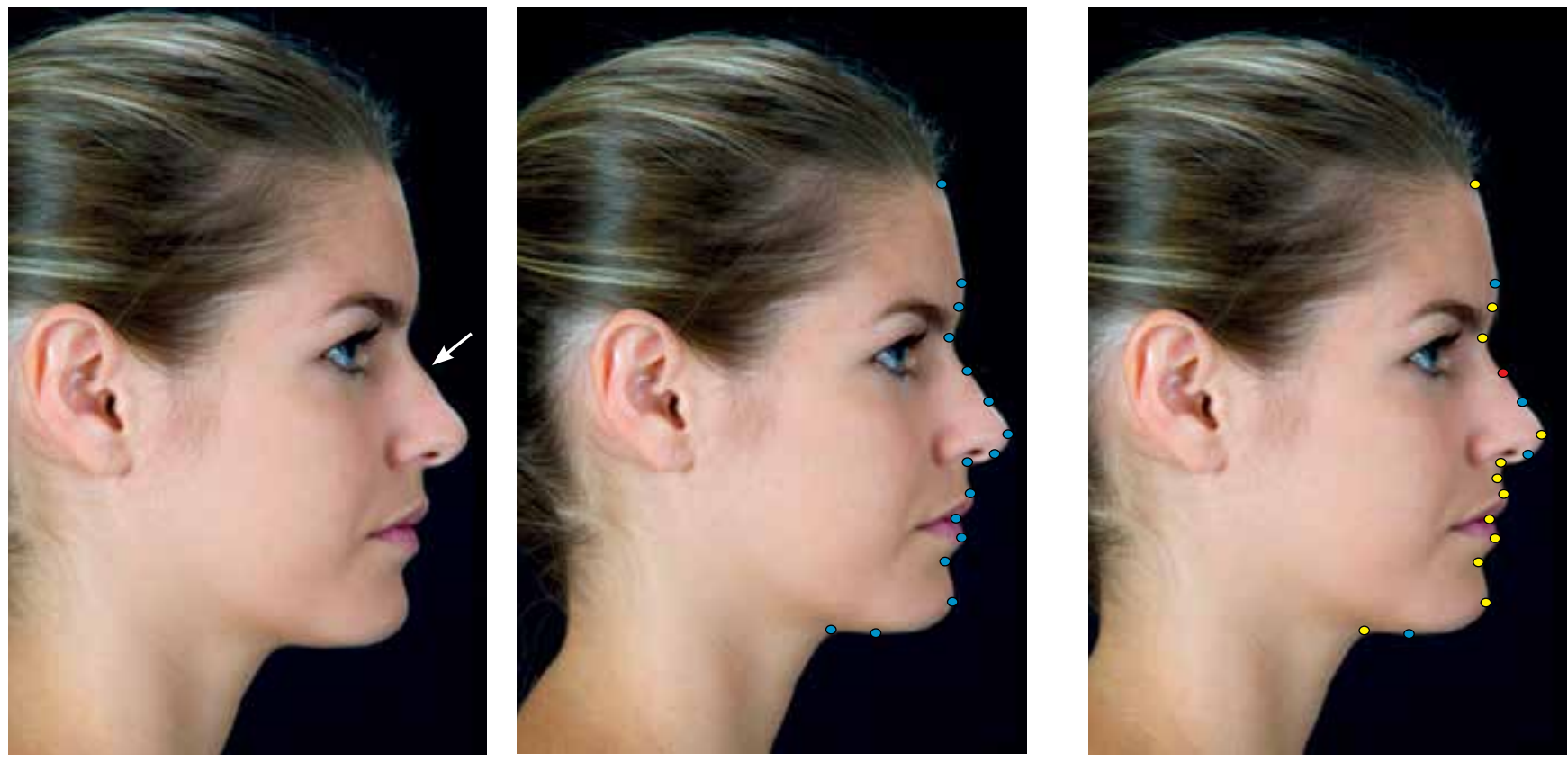

Figure 3 - Sagittal view with Interest Points (in blue), Reference Points (in yellow) and Discrepancy Points (in red). By manipulating the image on the computer a protuberance was added to the nasal dorsum (arrow) of the model, which created a new point of interest, that changed the esthetic perception that we call point of discrepancy.

the analyzed part, breaking or damaging its harmony, this flaw is considered as a Point of Discrepancy. Exaggerated or unexpected inclination of lines and structures can also be considered as Discrepancy Points. This evaluation and determination of the Discrepancy Points facilitate the perception of the problem. It is much easier to notice and quantify the error of a specific flaw when we identify these points. The attention given to Discrepancy Points leads the observer to a more careful analysis of the studied structure and eases the comprehension of specific needs. It is important to remember that Discrepancy Points have an intrinsic relation to Reference Points and it is necessary to have a clear idea of these last ones, so that the professional is alert for characteristics of normality. Only then the observer will have conditions to identify what is discrepant or has an unwanted alteration. The observation of Discrepancy Points allows us to comprehend the reason why some evaluations privilege the visualization of determined structures depending on the analyzed view. So, depending on the observation plan (sagittal or frontal) the esthetic evaluation of determined structure can be changed, and this change can be caused by the perception of Discrepancy Points that are found or not in a determined observation plan.

\section{CONCLUSION}

The Interest, Reference and Discrepancy Points are points that facilitate the visualization of analysis with esthetic perspective, allowing the professionals involved with esthetic orthodontic treatments to observe more carefully the evaluated structures.

\section{REFERENCES}

1. Ferreira, A. B. H. Novo Aurélio: o dicionário da língua portuguesa. Rio de Janeiro. Nova Fronteira. 1999.

2. Suassuna. A. Iniciação à estética. 10ำed. Rio de Janeiro. José Olympio. 2009

3. Yarbus, A. L. Eye movement and vision. New York. Plenum. 1967.

4. Farkas, L. G. Anthropometry of the head and face in medicine. New York. Elsevier. 1987. 